\title{
Mobile-Enhanced Peer Support for African Americans with Type 2 Diabetes: a Randomized Controlled Trial
}

\author{
Caroline Presley, MD, MPH ${ }^{7}$, April Agne, $M P H^{7}$, Tanya Shelton, RN, MSN, CDE ${ }^{2}$, \\ Robert Oster, $P h D^{\prime}$, and Andrea Cherrington, $M D, M P H^{\top}$
}

'Division of Preventive Medicine, Department of Medicine, School of Medicine, University of Alabama at Birmingham, Birmingham, AL, USA;

${ }^{2}$ Cooper Green Mercy Health Services, Birmingham, AL, USA.

BACKGROUND: Peer support has been shown to improve diabetes self-management and control, but no standard exists to link peer support interventions to clinical care.

OBJECTIVE: To compare a community-based diabetes self-management education (DSME) plus mobile health (mHealth)-enhanced peer support intervention to community-based diabetes self-management education (DSME) alone for African American adults with poorly controlled type 2 diabetes.

DESIGN: A randomized controlled trial.

PARTICIPANTS: African American adults, age $\geq 19$ years, receiving care within a safety-net healthcare system in Jefferson County, Alabama, with a diagnosis of type 2 diabetes and a hemoglobin Alc (A1C) $\geq 7.5 \%$.

INTERVENTIONS: Participants in the intervention group received community-based diabetes self-management education (DSME) plus 6 months of mHealth-enhanced peer support, including 12 weekly phone calls, then 3 monthly calls from community health workers, who used a novel web application to communicate with participants' healthcare teams. In the control group, participants received community-based DSME alone.

MAIN MEASURES: The primary outcome was AlC; secondary outcomes included diabetes distress, depressive symptoms, self-efficacy or confidence in their ability to manage diabetes, and social support. We used mixed models repeated measures analyses to assess for between-arm differences and baseline to follow-up changes.

KEY RESULTS: Of 120 participants randomized, 97 completed the study. Participants in intervention and control groups experienced clinically meaningful reduction in A1C, 10.1 (SD 1.7) to 9.6 (SD 1.9) and 9.8 (SD 1.7) to 9.1 (SD 1.9) respectively, $p=0.004$. Participants in the intervention group experienced a significantly larger reduction in diabetes distress compared to the control, 2.7 (SD 1.2) to 2.1 (1.0) versus 2.6 (SD 1.1) to 2.3 (SD 1.0) $p=$ 0.041 .

CONCLUSIONS: Community-based DSME with and without peer support led to improved glycemic control. Peer support linked to clinical care led to a larger reduction in diabetes distress, which has important implications for the overall wellbeing of adults with type 2 diabetes.

Electronic supplementary material The online version of this article (https://doi.org/10.1007/s11606-020-06011-w) contains supplementary material which is available to authorized users

Received December 4, 2019

Accepted June 23, 2020

Published online July 22, 2020
KEY WORDS: peer support; diabetes self-management education; mobile health.

$\mathrm{J}$ Gen Intern Med 35(10):2889-96 DOI: $10.1007 / \mathrm{s} 11606-020-06011-\mathrm{w}$ (c) Society of General Internal Medicine 2020

\section{BACKGROUND}

Persons with diabetes face demanding and complex daily selfmanagement activities including adherence to recommended diet, physical activity, medication(s), and blood glucose monitoring. ${ }^{1}$ Effective diabetes self-management can prevent or delay diabetes-related complications, but adherence to recommended behaviors is challenging. ${ }^{2,3}$ Non-Hispanic Blacks are disproportionately affected by diabetes and have a higher risk of diabetes-related morbidity and mortality than non-Hispanic Whites. ${ }^{4-11}$ Low-income, Black adults face considerable barriers to effective diabetes self-management.

Psychosocial factors influence diabetes self-management and outcomes in persons with diabetes. ${ }^{12,13}$ Diabetes distress, the emotional burden of living with diabetes, affects $36 \%$ of persons with diabetes and is closely linked to glycemic control. ${ }^{14-17}$ Social support refers to emotional, instrumental, or informational support and is linked to improved diabetes selfmanagement behaviors and clinical outcomes..$^{13,18-20}$

Peer support is defined as "support from a person who has knowledge from their own experiences with diabetes, either a person with diabetes, or a person affected by diabetes (e.g. immediate family member or caregiver)"; key features of peer support are provision of assistance in daily management, social and emotional support, linkages to clinical care and community resources, and ongoing support over time. ${ }^{21}$ Meta-analyses of peer support interventions in adults with diabetes have demonstrated significant improvement in glycemic control (hemoglobin A1c $[\mathrm{A} 1 \mathrm{C}])^{22,23}$ Multiple studies have demonstrated that peer support interventions are more effective for underserved or vulnerable populations. Among racial/ethnic minority populations, peer support interventions lead to a larger reduction in A1C than non-minority populations. ${ }^{24}$ Patients with low social support and health literacy or poor baseline diabetes self-management experience greater improvement in diabetes self-management and glycemic 
control with peer support interventions. ${ }^{25,26}$ Finally, peer support interventions are particularly beneficial for patients with elevated psychological distress or depressive symptoms who experience greater improvement in diabetes self-management and psychological well-being, as well as decreased hospitalizations. ${ }^{27,28}$

Although linkage to clinical care is a feature of peer support interventions, no standard guideline exists for implementation of peer support interventions, and interventions have generally been conducted in parallel to usual clinical care. ${ }^{23,29,30}$ Limited evidence exists on how to most effectively coordinate peer support with clinical care. This study evaluated a mobile health (mHealth) web application, which was developed using iterative user-centered design described previously, to facilitate coordination between peer supporters and the healthcare team. ${ }^{31}$ The study objective was to conduct a randomized controlled trial of a community-based diabetes self-management education (DSME) plus mobile health (mHealth)-enhanced peer support intervention compared with community-based diabetes selfmanagement education (DSME) alone in low-income African Americans with poorly controlled type 2 diabetes receiving care at a safety-net clinic.

\section{METHODS}

\section{Design}

This was a randomized-controlled trial of a communitybased DSME plus mHealth-enhanced peer support intervention compared with community-based DSME alone in low-income African Americans with type 2 diabetes.

\section{Setting}

This study was conducted through an existing partnership between the University of Alabama at Birmingham (UAB), Cooper Green Mercy Health Services (CGMHS), and Congregations for Public Health (CPH). CGMHS is a public-safety net system that provides healthcare services to residents of Jefferson County, Alabama. CPH is a 501(c)3 organization made up of a network of African American churches serving neighborhoods with high poverty rates with a mission of outreach to promote health equity. CPH had an existing community health worker program with Neighborhood Outreach Specialists (NOSeys).

\section{Participants}

Potential participants were identified using the CGMHS electronic database, mapped to $\mathrm{CPH}$ neighborhoods by zip code, and were mailed an opt-out invitation letter from the CGMHS diabetes clinic. This was followed by a recruitment phone call from the study coordinator, CGMHS- certified diabetes educator, or community health workers (CHWs) to invite potential participants to attend a community-based DSME course. Participants were eligible if they were African American, age 19 years or older, had poorly controlled type 2 diabetes (A1C $\geq 7.5 \%)$, and received care at CGMHS. Exclusion criteria including the following: limited life expectancy ( $<6$ months), lack of telephone access, anticipated move out of area within the next 6 months, non-community-dwelling, or non-English speaking. All participants provided written informed consent; the Institutional Review Board approved this study.

\section{Treatment Groups}

All participants in both arms completed community-based DSME course, which was held at $\mathrm{CPH}$ churches or CGMHS. Participants were screened, including point-ofcare A1C testing, at the time of the DSME course; eligible participants who provided informed consent were randomized to either the community-based DSME plus mHealthenhanced peer support intervention or the communitybased DSME alone (control) arm. Participants in the control arm received enhanced usual care through the completion of the community-based DSME course.

The intervention arm consisted of the community-based DSME course plus peer support provided by CHWs using a mHealth web application. Four CHWs were hired from $\mathrm{CPH}$ and CGMHS from the existing network of NOSeys. CHWs were between 39 and 66 years old, had completed some college or a college degree, and had diabetes themselves $(N=3)$ or a close relative with diabetes $(N=1){ }^{31}$ $\mathrm{CHWs}$ completed investigator-developed training, which has been previously described, focused on communication, problem-solving, goal setting, and principles of motivational interviewing, to prepare $\mathrm{CHWs}$ to provide the key functions of peer support to intervention participants: assistance in applying diabetes self-management in daily life, emotional and social support, linkage to clinical care, and ongoing, as-needed support. ${ }^{21,31} \mathrm{CHWs}$ completed an initial face-to-face visit with participants at the community-based DSME course, then completed weekly phone calls with participants for 3 months, followed by monthly calls for 3 months. CHWs helped participants to choose behavioral goals related to diabetes selfmanagement and tracked participants' progress over time. CHWs also held monthly support groups for study participants.

Throughout the intervention, CHWs used a mHealth web-based application to connect to members of the healthcare team. The application was developed for this study using iterative user-centered design described previously. ${ }^{31,32}$ The application had three core features: (1) contact tracking and call reminder system; (2) secure communication system which allowed CHWs to message members of the healthcare team; and (3) a progress report 
system. CHWs generated reports with information on medication adherence, barriers identified by participants, and progress towards behavioral goals.

\section{Data Collection and Outcomes}

Participants completed study visits at baseline (community-based DSME course) and 6-month followup. Visits included an interviewer-administered questionnaire comprised of participant demographics, health status, validated self-report measures of psychosocial variables, and diabetes self-management behaviors detailed below. A1C was assessed via point-of-care testing using Bayer Now+ testing kits.

The primary outcome was change in glycemic control (A1C) from baseline to 6 months. We included multiple secondary patient-reported outcomes - diabetes distress, depressive symptoms, quality of life, social support, and self-efficacy.

Diabetes distress was measured using the 17-item Diabetes Distress Scale (DDS), which evaluates the degree to which an item is bothering a participant over the past month. ${ }^{15}$ DDS has four valid subscales assessing emotional burden, physician-related distress, regimen-related distress, and interpersonal distress. Participants respond on a 6-point Likert scale from 1 (not a problem) to 6 (a very serious problem). Total scale and subscales are scored by obtaining the mean item score, yielding a possible range of 1-6. For the total scale and subscales, a score of $<2$ indicates little/no diabetes distress, 2-2.9 moderate distress, and $\geq 3$ severe distress. ${ }^{33}$

We measured depressive symptoms, including cognitive/affective and somatic symptoms, using the Center for Epidemiologic Studies Depression scale (CES-D), a 10 -item self-report scale. ${ }^{34-36}$ Participants indicate the frequency of symptoms in the preceding week by choosing from a scale of 0 (rarely or none of the time $[<1$ day]) to 3 (most or all of the time [5-7 days]). A higher score indicates more depressive symptoms; a score of $\geq 10$ is a positive screen, suggesting possible depression. ${ }^{35}$

We assessed the quality of life using the EuroQol visual analog scale (EQ-VAS) which asked participants "We would like to know how good or bad your health is today," responses on a visual scale from 0 (the worst health you can imagine) to 100 (the best health you can imagine). ${ }^{37}$

Self-efficacy was measured using the 8-item Perceived Diabetes Self-Management Scale (PDSMS) ${ }^{38}$ Participants respond on a 5-point Likert scale from 1 (strongly disagree) to 5 (strongly agree) giving a score of 8-40; a higher score indicates more confidence in managing one's diabetes. $^{38}$

We assessed participants' perceived social support from and satisfaction with support from their diabetes healthcare team with two items- "How much support do you get from your diabetes healthcare team for dealing with your diabetes?" and "How satisfied are you with the support you get from your diabetes healthcare team for dealing with your diabetes?" respectively. ${ }^{20}$ Participants responded on a 5-point Likert scale-a higher number indicates greater support or satisfaction; we report the results of each item separately. We assessed perceived social support from family and friends for diabetes management with 5 items including "My family and friends help and support me a lot in caring for my diabetes?" and "My family or friends make it more difficult for me to care for my diabetes." 39 Participants responded on a 5point Likert scale-higher number indicates greater support; responses for the 5 items were averaged to generate the family/friend support score.

We collected aggregate web application usage data and conducted a follow-up survey with a subset of intervention participants $(N=22)$ to assess intervention fidelity.

\section{Statistical Analysis}

Descriptive statistics were calculated for the total sample and separately for each arm. All analyses were performed on an intention-to-treat basis. Continuous variables were assessed for normality using box plots, stem-and-leaf plots, and normal probability plots, and it was determined that these variables were at least approximately normally distributed. We had very small amounts of missing data for two variables, income and social support, and

Table 1 Participant Characteristics at Baseline

\begin{tabular}{|c|c|c|c|c|}
\hline & Total, $N=97$ & Intervention, $N=62$ & Control, $N=35$ & $p$ value \\
\hline Age in years, mean $(\mathrm{SD})$ & $54.9(8.3)$ & $54.6(8.2)$ & $55.5(8.5)$ & 0.64 \\
\hline Female, $N(\%)$ & $69(71.1)$ & $42(67.7)$ & $27(77.1)$ & 0.33 \\
\hline Education, $N(\%)$ & & & & 0.99 \\
\hline Some high school & 19 (19.6) & $12(19.4)$ & $7(20.0)$ & \\
\hline High school diploma or equivalent & $33(34.0)$ & $21(33.9)$ & $12(34.3)$ & \\
\hline Some college & $32(33.0)$ & $21(33.9)$ & $11(31.4)$ & \\
\hline College degree & $13(13.4)$ & $8(12.9)$ & $5(14.3)$ & \\
\hline Income per month in dollars, mean (SD) & $1110(1375)$ & $1154(1676)$ & $1032(567)$ & 0.61 \\
\hline Duration of diabetes in years, mean (SD) & $8.7(7.6)$ & $8.8(7.7)$ & $8.5(7.6)$ & 0.84 \\
\hline Insulin use, $N(\%)$ & $57(58.8)$ & $36(58.1)$ & $21(60.0)$ & 0.85 \\
\hline Body mass index, mean (SD) & $35.2(8.1)$ & $35.6(8.1)$ & $34.4(8.0)$ & 0.47 \\
\hline
\end{tabular}


complete data for the other variables that we report on. Out of the 97 participants in the study, 4 had missing data for income (3 from intervention, 1 from the control group), 1 had missing data for social support measures at baseline (from intervention group), and 3 had missing data for social support at 6-month follow-up (2 from intervention, 1 from the control group). Given the small amounts of missing data and also the exploratory nature of our study, multiple imputation was not performed for missing data. Statistical tests were two-sided and were performed using a significance level of 5\%. Statistical analyses were conducted using SAS (version 9.4; SAS Institute, Cary, $\mathrm{NC}$ ).

Comparisons of baseline characteristics, psychosocial variables, and health status between the participants in the two study arms (Table 1), and also between participants who completed the study and those lost to follow-up (Table 3 in the supplementary material), were performed using two-group $t$ test for continuous variables and twogroup chi-square test for categorical variables. Betweenarm differences and baseline to follow-up changes were assessed simultaneously using mixed models repeated measures analyses for $\mathrm{A} 1 \mathrm{C}$, clinical variables, and psychosocial variables (Table 2). An unstructured covariance matrix was assumed for these analyses. The TukeyKramer multiple comparison test was then used for post hoc comparisons. These models included terms for study arm (intervention, control), time (baseline, 6 months), and the study arm by time interaction. We then repeated these analyses for the variables listed in Table 2 controlling for the following factors: age, gender, insulin use, and duration of diabetes. These factors were selected because they have previously been associated with A1C and other clinical and psychosocial factors. ${ }^{14,40,41}$

\section{RESULTS}

A total of 240 individuals were screened to participate in the study (Fig. 1: CONSORT diagram). Of these, 120 participants were randomized; 70 to intervention and 50 to control; 8 participants from the intervention and 15 participants from the control group were lost to followup $(p=0.01)$. Participants lost to follow-up were more likely to be male or in the control group; otherwise, those lost to follow-up were similar to study completers.

We included the 97 African American participants with poorly controlled type 2 diabetes who completed the study in our analysis. Table 1 describes the participants at baseline. On average, participants were 55 years old (standard deviation [SD] 8.3); 71\% female. At baseline, the mean A1C was 10.0 (1.7) and mean DDS score 2.7 (1.1). Participant demographic and health status characteristics were similar between treatment arms, except interpersonal distress scores were higher in the intervention group compared with those in the control, 2.6 (1.5) versus 2.0 (1.0) $(p=0.017)$.

\section{Primary Outcomes}

The primary outcome was change in $\mathrm{A} 1 \mathrm{C}$ from baseline to 6 months. There was a significant and clinically meaningful reduction in $\mathrm{A} 1 \mathrm{C}$ in both intervention and control groups, 10.1 (SD 1.7) to 9.6 (SD 1.9) and 9.8 (SD 1.7) to 9.1 (SD 1.9) respectively, $p=0.004$ (Table 2). There was not a statistically significant difference in change in A1C between intervention and control groups $(p=0.21)$ nor was there a statistically significant group $\times$ time interaction $(p=0.75)$

\section{Secondary Outcomes}

We assessed change in psychosocial variables - diabetes distress, depressive symptoms, social support, self-efficacy, and quality of life-from baseline to 6-month followup (Table 2). Participants in both treatment groups experienced a significant reduction in diabetes distress between baseline and 6 months $(<0.001)$; the change in diabetes distress was significantly larger in the intervention compared with that in the control group, 2.7 (SD 1.2) to 2.1 (1.0) versus 2.6 (SD 1.1) to 2.3 (SD 1.0) $(p=0.041)$. Participants in both treatment groups experienced a significant reduction in each domain of diabetes distress; the change in regimen-related distress was significantly larger in the intervention compared with that in the control group, 2.9 (1.3) to 2.2 (1.3) versus 2.9 (1.4) to 2.7 (1.3) $(p=0.046)$. Participants in both groups had improved perceived social support; this did not differ between the intervention and control group $(p=0.46)$. Participants in both groups experienced an increase in self-efficacy $(p<$ $0.001)$. Although the increase in self-efficacy was larger in the intervention group, 26.1 (6.7) to 29.4 (6.2), than in the control group, $27.2(6.3)$ to $28.2(6.6)$, this difference was not statistically significant $(p=0.058)$. Depressive symptoms and quality of life did not differ significantly from baseline to 6-month follow-up. Results obtained from analyses for $\mathrm{A} 1 \mathrm{C}$ and variables in Table 2 after adjusting for age, gender, insulin use, and duration of diabetes (results not shown) were nearly identical to those obtained from the unadjusted analyses, suggesting that these factors do not moderate the effect of the intervention and results presented in Table 2 cannot be explained by effects of these factors.

\section{mHealth Web Application Usage and Intervention Fidelity}

Participants set 125 behavioral goals, focused on physical activity (44\%) and diet (37\%). During the study, 314 unique messages regarding 53 participants $(85 \%$ of intervention participants) were sent between $\mathrm{CHWs}$ and 
Table 2 Group and Time Comparisons for Intervention vs Control

\begin{tabular}{|c|c|c|c|c|c|c|c|}
\hline \multirow[b]{2}{*}{ Mean (SD) } & \multicolumn{2}{|c|}{ Intervention } & \multicolumn{2}{|l|}{ Control } & \multirow{2}{*}{$\begin{array}{l}p \text { value, } \\
\text { group }\end{array}$} & \multirow{2}{*}{$\begin{array}{l}p \text { value, } \\
\text { time }\end{array}$} & \multirow{2}{*}{$p$ value, group $\times$} \\
\hline & Baseline & 6 months & Baseline & 6 months & & & \\
\hline $\mathrm{A} 1 \mathrm{C}$ & $10.1(1.7)$ & $9.6(1.9)$ & $9.8(1.7)$ & $9.1(1.9)$ & 0.21 & 0.004 & 0.75 \\
\hline Depressive symptoms & $10.2(6.2)$ & $10.5(6.3)$ & $9.7(5.8)$ & $10.8(6.8)$ & 0.94 & 0.21 & 0.48 \\
\hline Diabetes distress & $2.7(1.2)$ & $2.1(1.0)$ & $2.6(1.1)$ & $2.3(1.0)$ & 0.86 & $<0.001$ & 0.041 \\
\hline \multicolumn{8}{|l|}{ Diabetes distress domains } \\
\hline Emotional burden & $2.9(1.4)$ & $2.5(1.4)$ & $2.7(1.4)$ & $2.6(1.3)$ & 0.73 & 0.011 & 0.14 \\
\hline Physician-related & $2.3(1.3)$ & $1.7(1.1)$ & $2.4(1.4)$ & $2.1(1.2)$ & 0.25 & $<0.001$ & 0.38 \\
\hline Regimen-related & $2.9(1.3)$ & $2.2(1.3)$ & $2.9(1.4)$ & $2.7(1.3)$ & 0.37 & $<0.001$ & 0.046 \\
\hline Interpersonal & $2.6(1.5)$ & $1.9(2.2)$ & $2.0(1.0)$ & $1.8(1.2)$ & 0.10 & 0.003 & 0.089 \\
\hline Self-efficacy & $26.1(6.7)$ & $29.4(6.2)$ & $27.2(6.3)$ & $28.2(6.6)$ & 0.95 & $<0.001$ & 0.058 \\
\hline \multicolumn{8}{|l|}{ Social support } \\
\hline From healthcare team & $4.4(1.0)$ & $4.6(0.8)$ & $4.2(1.3)$ & $4.6(0.9)$ & 0.33 & 0.025 & 0.46 \\
\hline Satisfaction with healthcare team & $4.3(1.1)$ & $4.6(0.9)$ & $4.1(1.4)$ & $4.7(0.8)$ & 0.62 & 0.001 & 0.29 \\
\hline \multicolumn{8}{|l|}{ support } \\
\hline From family and friends & $4.0(0.9)$ & $4.3(0.7)$ & $4.2(0.8)$ & $4.3(0.8)$ & 0.30 & 0.015 & 0.46 \\
\hline Quality of life & $\begin{array}{l}60.5 \\
(19.9)\end{array}$ & $\begin{array}{l}63.4 \\
(22.9)\end{array}$ & $\begin{array}{l}58.5 \\
(21.1)\end{array}$ & $\begin{array}{l}62.6 \\
(17.0)\end{array}$ & 0.70 & 0.11 & 0.81 \\
\hline
\end{tabular}

participants' healthcare team. From the participants' follow-up survey, $72.7 \%$ reported having recommended number of contacts with CHWs (at least 12 weekly plus 3 monthly contacts), $13.6 \%$ reported between 6 and 12 contacts. All participants reported that $\mathrm{CHW}$ contacts covered the three core study content areas-medication taking, behaviors and goals, and other concerns about diabetes.

\section{DISCUSSION}

In this randomized-controlled trial of a community-based DSME plus mHealth-enhanced peer support intervention compared with enhanced usual care with communitybased DSME alone among low-income African American adults with poorly controlled type 2 diabetes, both groups experienced significant and clinically significant improvement in glycemic control (A1C). We used targeted

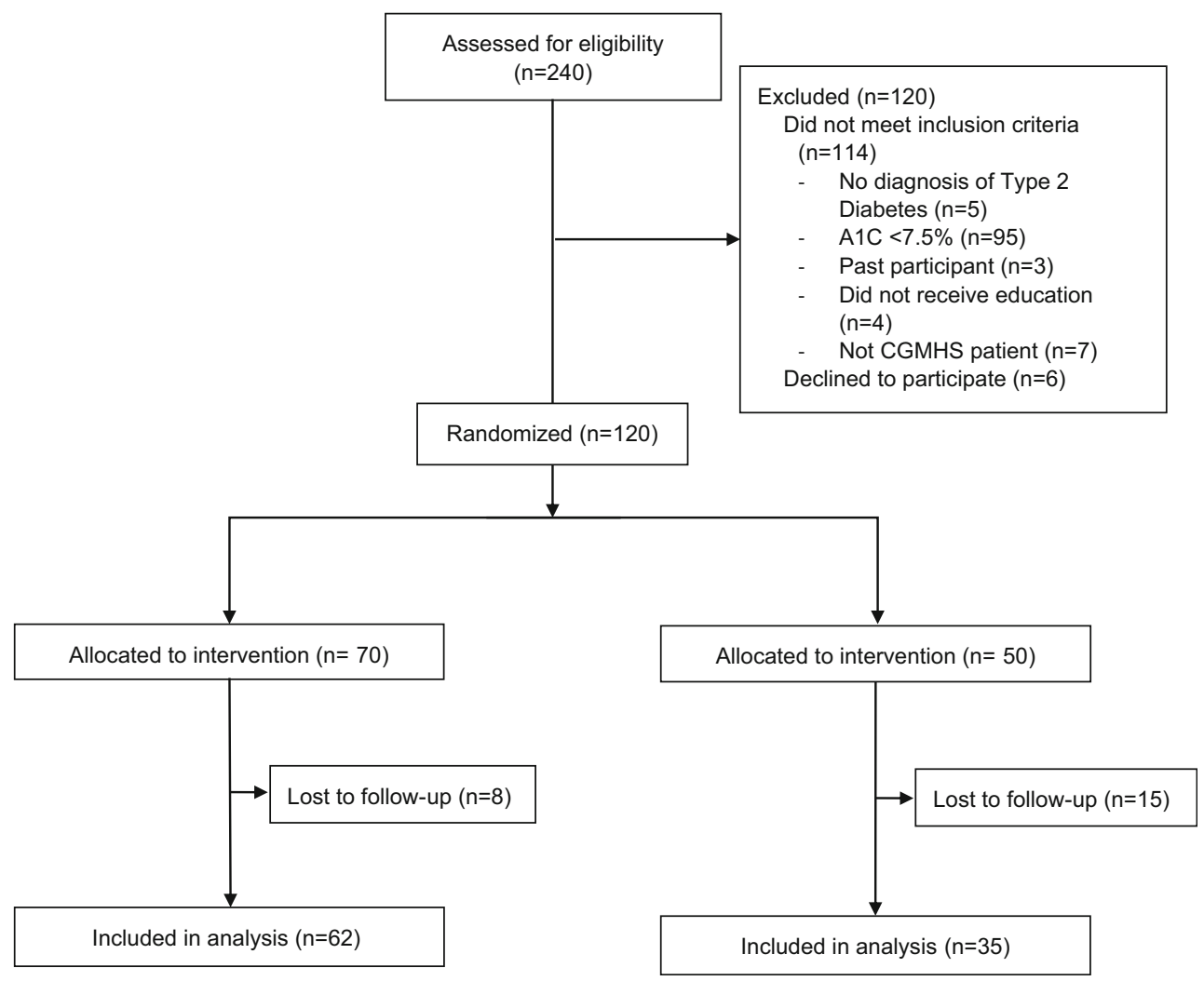

Figure 1 Consort diagram. 
outreach and community-based DSME to address barriers that many low-income African Americans may experience in receiving DSME-access, transportation, work, or childcare obligations. ${ }^{42}$ A prior evaluation of barriers to attending a DSME class at CGMHS demonstrated that work, other obligations, and transportation were commonly reported barriers.

Participants in the community-based DSME plus peer support arm experienced a larger reduction in diabetes distress than the enhanced usual care arm. Diabetes distress refers to the fears, worries, and frustrations that people experience while living with diabetes; it was present in $66 \%$ of study participants at baseline. ${ }^{12,15,43}$ Diabetes distress is associated with reduced adherence to diabetes self-management behaviors and lower quality of life. ${ }^{16}$, 17,44 African Americans experience higher diabetes distress than non-Hispanic Whites. ${ }^{45}$ In addition to an association with worse glycemic control, psychological distress is linked to increased risk of cardiovascular events and death in persons with diabetes; limited data exists on the link between diabetes-specific distress and cardiovascular disease risk in persons with diabetes. ${ }^{46,47}$ The intervention arm experienced a differential improvement in diabetes distress primarily driven by improved regimenrelated distress, as well as a trend towards improved diabetes self-efficacy compared with the enhanced usual care group. These results suggest that peer support plays an important role in reducing distress and improving selfconfidence related to diabetes self-management behaviors in adults with poorly controlled type 2 diabetes.

A strength of this study was the use of an innovative communication system - a web-based application, Diabetes Connect, designed specifically for CHWs to allow for coordination between CHWs and the healthcare team-in the community-based DSME plus mHealth-enhanced peer support arm of the study. ${ }^{31}$ The application was utilized by CHWs for $85 \%$ of the intervention arm participants. Care coordination is a key feature of peer support. ${ }^{21}$

\section{Limitations}

Our study does have limitations. The sample size of 97 may have limited our ability to detect a significant difference in A1C results between groups. Our target study population were African American adults with poorly controlled type 2 diabetes, which may limit the generalizability of these findings to other populations. Overall study retention was approximately $81 \%$. More participants in the enhanced usual care arm were lost to follow-up than in the intervention arm, which may introduce selection bias. The follow-up period of 6 months may also be a limitation; a longer follow-up period may have provided an opportunity to see a beneficial and differential impact of reduced distress and improved self-efficacy in the intervention group on diabetes outcomes including A1C. Given the limitations of the data on CHW-participant interactions or the use of web-based application, we are unable to determine the "dose-response" effect of intervention components.

\section{Conclusions}

Our study demonstrates that targeted community-based DSME with and without peer support improved glycemic control among low-income, African American adults with poorly controlled type 2 diabetes. The peer support intervention, which included a web application to allow linkage to clinical care, led to a larger reduction in diabetes distress, which has important implications for the overall wellbeing of adults with type 2 diabetes. Future studies should confirm our findings in larger, diverse samples (including those with elevated diabetes distress) with an extended follow-up period.

Acknowledgments: We would like to acknowledge the tireless efforts and hard work of our study team and support staff. We especially want to thank our Community Health Workers for their hard work, kindness, and the support they provided to participants. We are sincerely grateful to our community partners and churches that facilitated the community outreach. Finally, we are extremely appreciative of the patience and dedication of the IT team.

Corresponding Author: Caroline Presley, MD, MPH; Division of Preventive Medicine, Department of Medicine, School of Medicine, University of Alabama at Birmingham, Birmingham, AL, USA (e-mail: capresley@uabmc.edu).

Funding Information This project was supported by the University of Alabama at Birmingham's (UAB) Diabetes Research Center (Award Number P3O DK-079626) and the UAB Obesity Training Program (Award Number T32 DK-062710) from the National Institute of Diabetes and Digestive and Kidney Diseases.

\section{Compliance with Ethical Standards:}

All participants provided written informed consent; the Institutional Review Board approved this study.

Conflict of Interest: The authors declare that they do not have a conflict of interest.

Disclaimer: The content is solely the responsibility of the authors and does not necessarily represent the official views of the National Institute of Diabetes and Digestive and Kidney Diseases or the National Institutes of Health. Funding was also provided by grants from the American Diabetes Association [1-12-CT-16] (Dr. Cherrington) and the Agency for Healthcare Research and Guality [K12 HSO19465] (PI Saag/Project PI Dr. Cherrington).

\section{REFERENCES}

1. American Diabetes Association. Lifestyle management: Standards of medical care in diabetes, 2019. Diabetes Care. 2019;42(January):S46S60. https://doi.org/10.2337/dc19-S005

2. Beck J, Greenwood DA, Blanton L, et al. 2017 National Standards for Diabetes Self-Management Education and Support. Diabetes Care. 2017;40(10):1409-1419. https://doi.org/10.2337/dci17-0025

3. Safford MM, Russell L, Suh D, Roman S, Pogach L. How Much Time Do Patients with Diabetes Spend on Self-Care ? J Am Board Fam Pract. 2005; 18(4):262-270.

4. Centers for Disease Control and Prevention. National Diabetes Statistics Report, 2017. Atlanta, GA; Centers for Disease Control and Prevention, U.S. Dept of Health and Human Services; 2017. 
5. Spanakis EK, Golden SH. Race/Ethnic Difference in Diabetes and Diabetic Complications. Curr Diab Rep. 2013;13(6). 10.1007/s11892 013-0421-9

6. Young BA, Maynard C, Boyko EJ. Racial Differences in Diabetic Nephropathy, Cardiovascular Disease, and Mortality in a National Population of Veterans. Diabetes Care. 2003;26(8):2392-2399.

7. Walker RJ, Gebregziabher M, Martin-Harris B, Egede LE. Relationship between social determinants of health and processes and outcomes in adults with type 2 diabetes: Validation of a conceptual framework. BMC Endocr Disord. 2014;14(1):1-10. https://doi.org/10.1186/1472-682314-82

8. Robbins JM, Vaccarino V, Zhang $\mathbf{H}$, Kasl S V. Socioeconomic status and type 2 diabetes in African American and non-Hispanic white women and men: evidence from the Third National Health and Nutrition Examination Survey. Am J Public Health. 2001;91(1):76-83.

9. Piccolo RS, Subramanian S V., Pearce N, Florez JC, McKinlay JB. Relative contributions of socioeconomic, local environmental, psychosocial, lifestyle/behavioral, biophysiological, and ancestral factors to racial/ ethnic disparities in type 2 diabetes. Diabetes Care. 2016;39(7):12081217. https://doi.org/10.2337/dc15-2255

10. Brown AF, Ettner SL, Piette J, et al. Socioeconomic position and health among persons with diabetes mellitus: A conceptual framework and review of the literature. Epidemiol Rev. 2004;26:63-77. https://doi. org/10.1093/epirev/mxh002

11. Miech RA, Kim J, McConnell C, Hamman RF. A Growing Disparity in Diabetes-Related Mortality: US Trends 1989-2005. Am J Prev Med. 2009;36(2):126-132. https://doi.org/10.1016/j.amepre.2008.09.041

12. Aikens JE. Prospective associations between emotional distress and poor outcomes in type 2 diabetes. Diabetes Care. 2012;35(12):2472-2478. https://doi.org/10.2337/dc12-0181

13. Miller TA, DiMatteo MR. Importance of family/social support and impact on adherence to diabetic therapy. Diabetes, Metab Syndr Obes Targets Ther. 2013;6:421-426. https://doi.org/10.2147/DMSO.S36368

14. Perrin NE, Davies MJ, Robertson N, Snoek FJ, Khunti K. The prevalence of diabetes-specific emotional distress in people with Type 2 diabetes: a systematic review and meta-analysis. Diabet Med. 2017;34(11). 10.1111/dme.13448

15. Polonsky WH, Fisher L, Earles J, et al. Assessing Psychosocial Distress in Diabetes: Development of the Diabetes Distress Scale. Diabetes Care 2005;28(3):626-631.

16. Fisher L, Glasgow RE, Strycker LA. The Relationship Between Diabetes Distress and Clinical Depression With Glycemic Control Among Patients With Type 2 Diabetes. Diabetes Care. 2010;33(5):1034-1036. https://doi org/10.2337/dc09-2175.

17. Glasgow RE, Hessler D, Mullan JT, Arean P, Fisher L, Masharani U. Diabetes Distress but Not Clinical Depression or Depressive Symptoms Is Associated With Glycemic Control in Both Cross-Sectional and Longitudinal Analyses. Diabetes Care. 2009;33(1):23-28. https://doi.org/10. 2337/dc09-1238

18. Karlsen B, Oftedal B, Bru E. The relationship between clinical indicators, coping styles, perceived support and diabetes-related distress among adults with type 2 diabetes. J Adv Nurs. 2012;68(2):391-401. https://doi.org/10.1111/j.1365-2648.2011.05751.x

19. Pintaudi B, Lucisano G, Gentile S, et al. Correlates of diabetes-related distress in type 2 diabetes: Findings from the benchmarking network for clinical and humanistic outcomes in diabetes (BENCH-D) study. $J$ Psychosom Res. 2015;79(5):348-354. https://doi.org/10.1016/j.jpsychores.2015.08.010

20. Tang TS, Brown MB, Funnell MM, Anderson RM. Social Support, Quality of Life, and Self-Care Behaviors Among African Americans With Type 2 Diabetes. Diabetes Educ. 2008;34(2):266-276. https://doi.org/10. $1177 / 0145721708315680$

21. What is Peer Support? Peers for Progress. http://peersforprogress.org/ learn-about-peer-support/what-is-peer-support/. Accessed June 27. 2019 .

22. Krishnamoorthy Y, Sakthivel M, Sarveswaran G, Eliyas SK. Effectiveness of peer led intervention in improvement of clinical outcomes among diabetes mellitus and hypertension patients-A systematic review and meta-analysis. Prim Care Diabetes. 2019;13(2):158-169. https://doi.org/ 10.1016/j.pcd.2018.11.007

23. Zhang $\mathbf{X}$, Yang S, Sun $\mathbf{K}$, Fisher EB, Sun $\mathbf{X}$. How to achieve better effect of peer support among adults with type 2 diabetes: A meta-analysis of randomized clinical trials. Patient Educ Couns. 2016;99(2):186-197. https://doi.org/10.1016/j.pec.2015.09.006
24. Patil SJ, Ruppar T, Koopman RJ, et al. Peer Support Interventions for Adults With Diabetes: A Meta-Analysis of Hemoglobin Alc Outcomes. Ann Fam Med. 2016;14:540-551. https://doi.org/10.1370/afm. 1982.

25. Piette JD, Resnicow K, Choi H, Heisler M. A Diabetes Peer Support Intervention that Improved Glycemic Control: Mediators and Moderators of Intervention Effectiveness. Chronic Illn. 2013;9(4):1-12. https://doi. org/10.1177/1742395313476522.

26. Moskowitz D, Thom DH, Hessler D, Ghorob A, Bodenheimer T. Peer Coaching to Improve Diabetes Self-Management: Which Patients Benefit Most ? J Gen Intern Med. 2012;28(7):938-942. https://doi.org/10.1007/ s11606-013-2367-7

27. Chan JCN, Sui Y, Oldenburg B, et al. Effects of telephone-based peer support in patients with type 2 diabetes mellitus receiving integrated care: A randomized clinical trial. JAMA Intern Med. 2014;174(6):972-981. https://doi.org/10.1001/jamainternmed.2014.655

28. Cherrington AL, Khodneva Y, Richman JS, Andreae SJ, Gamboa C, Safford MM. Impact of peer support on acute care visits and hospitalizations for individuals with diabetes and depressive symptoms: A cluster-randomized controlled trial. Diabetes Care. 2018;41(12):24632470. https://doi.org/10.2337/dc18-0550

29. Cherrington A, Ayala GX, Amick H, Allison J, Corbie-Smith G, Scarinci I. Implementing the Community Health Worker Model within Diabetes Management: Challenges and Lessons Learned from Programs across the U.S. Diabetes Educ. 2008;34(5):824-833. https://doi.org/10. $1177 / 0145721708323643$

30. Fisher E, Ballesteros J, Bhushan N, et al. Key Features Of Peer Support In Chronic Disease Prevention And Management. Health Aff. 2015;9:1523-1530. https://doi.org/10.1377/hlthaff.2015.0365

31. Cherrington AL, Agne AA, Lampkin Y, et al. Diabetes Connect: Developing a Mobile Health Intervention to Link Diabetes Community Health Workers with Primary Care. J Ambul Care Manage. 2015;38(4):333-342. https://doi.org/10.1038/nm.2451.A

32. Norman D. User-Centered System Design: New Perspectives on HumanComputer Interaction. In: The Psychology of Everyday Things. ; 1988.

33. Fisher L, Hessler DM, Polonsky WH, Mullan J. When is diabetes distress clinically meaningful? Establishing cut points for the diabetes distress scale. Diabetes Care. 2012;35(2):259-264. https://doi.org/10. 2337/dc11-1572

34. Radloff LS. Applied Psychological Measurement The CES-D Scale : A Self-Report Depression Scale for Research in the General Population. Appl Psychol Meas. 1977;1(3):385-401. https://doi.org/10.1177/ 014662167700100306

35. Andresen EM, Malmgren JA, Carter WB, Patrick DL. Screening for depression in well older adults: Evaluation of a short form of the CES-D (Center for Epidemiologic Studies Depression Scale). Am J Prev Med. 1994;10(2):77-84. https://doi.org/10.4236/health.2013.53A078

36. Nguyen HT, Kitner-Triolo M, Evans MK, Zonderman AB. Factorial invariance of the CES-D in low socioeconomic status African Americans compared with a nationally representative sample. Psychiatry Res. 2004;126(2):177-187. https://doi.org/10.1016/j.psychres.2004.02.004

37. Clarke P, Gray A, Holman R. Estimating utility values for health states of type 2 diabetic patients using the EQ-5D (UKPDS 62). Med Decis Mak. 2002;22(4):340-349. https://doi.org/10.1177/027298902400448902

38. Wallston KA, Rothman RL, Cherrington AL. Psychometric Properties of the Perceived Diabetes Self-Management Scale (PDSMS). J Behav Med 2007;30:395-401. https://doi.org/10.1007/s10865-007-9110-y

39. Rosland AM, Kieffer E, Israel B, et al. When is social support important? The association of family support and professional support with specific diabetes self-management behaviors. J Gen Intern Med 2008;23(12): 1992-1999. https://doi.org/10.1007/s11606-008-0814-7

40. Fisher L, Mullan JT, Skaff MM, Glasgow RE, Arean P, Hessler D. Predicting Diabetes Distress in Patients with Type 2 Diabetes: a Longitudinal Study. Diabet Med. 2009;26(6):622-627. https://doi.org/ 10.1111/j.1464-5491.2009.02730.x.

41. Dinardo MM, Sereika SM, Korytkowski M, et al. Current Smoking: An Independent Predictor of Elevated AlC in Persons With Type 2 Diabetes. Diabetes Educ. 2019;45(2):146-154. https://doi.org/10.1177/ 0145721719829068

42. Kahn LS, Glaser K, Fox CH, Patterson A. Diabetes educators in safetynet practices: A qualitative study. Diabetes Educ. 2011;37(2):212-219. https://doi.org/10.1177/0145721710397385

43. Nicolucci A, Kovacs Burns K, Holt RIG, et al. Diabetes Attitudes, Wishes and Needs second study (DAWN2 $2^{\mathrm{TM}}$ ): Cross-national benchmarking of diabetes-related psychosocial outcomes for people with diabetes. Diabet Med. 2013;30(7):767-777. https://doi.org/10.1111/dme.12245 
44. Zagarins SE, Allen NA, Garb JL, Welch G. Improvement in glycemic control following a diabetes education intervention is associated with change in diabetes distress but not change in depressive symptoms. $J$ Behav Med. 2012;35(3):299-304. https://doi.org/10.1007/s10865-0119359-Z

45. Peyrot M, Egede LE, Campos C, et al. Ethnic differences in psychological outcomes among people with diabetes: USA results from the second Diabetes Attitudes, Wishes, and Needs (DAWN2) study. Curr Med Res Opin. 2014;30(11):2241-2254. https://doi.org/10.1185/03007995. 2014.947023
46. Dalsgaard EM, Vestergaard M, Skriver M V., et al. Psychological distress, cardiovascular complications and mortality among people with screen-detected type 2 diabetes: Follow-up of the ADDITION-Denmark trial. Diabetologia. 2014;57(4):710-717. https://doi.org/10.1007/ s00125-014-3165-4

47. Hackett RA, Steptoe A. Psychosocial Factors in Diabetes and Cardiovascular Risk. Curr Cardiol Rep. 2016;18(10). 10.1007/s11886-0160771-4

Publisher's Note: Springer Nature remains neutral with regard to jurisdictional claims in published maps and institutional affiliations. 